\title{
Mostra da Qualidade: Interação e Melhoria de Processos
}

Autores: Da Silva, L.M. ; Guimares, K.P.S.Q. ; Cossermelli, M. ; Arias.V. e Moraes, D.P.

\section{Introdução}

A Gestão da Qualidade e Riscos é uma unidade de apoio importante para disseminação da Segurança do Paciente e Melhoria Contínua dos processos, exercendo um papel de destaque nas instituições de saúde, estimulando práticas que promovam a interação entre as áreas e o uso de ferramentas da Qualidade. Após o benchmarking em um hospital de referência, foi criada a "Mostra da Qualidade", tendo com objetivo expor as boas práticas desenvolvidas pelas áreas, além de ser um momento para reconhecimento do desempenho das equipes.

\section{Método}

Exposição das boas práticas da instituição. Descrição de processos de melhoria utilizando a ferramenta Ishikawa para análise de causa, e a demonstração dos resultados obtidos. Para garantir a imparcialidade na avaliação dos trabalhos, a comissão julgadora foi formada por avaliadores externos. Foram oferecidos prêmios para o 1ํ, $2^{\circ}$ e $3^{\circ}$ lugares, e para o vencedor do voto popular - estratégia utilizada para incentivar a visitação à Mostra e para estimular o envolvimento e participação das áreas.

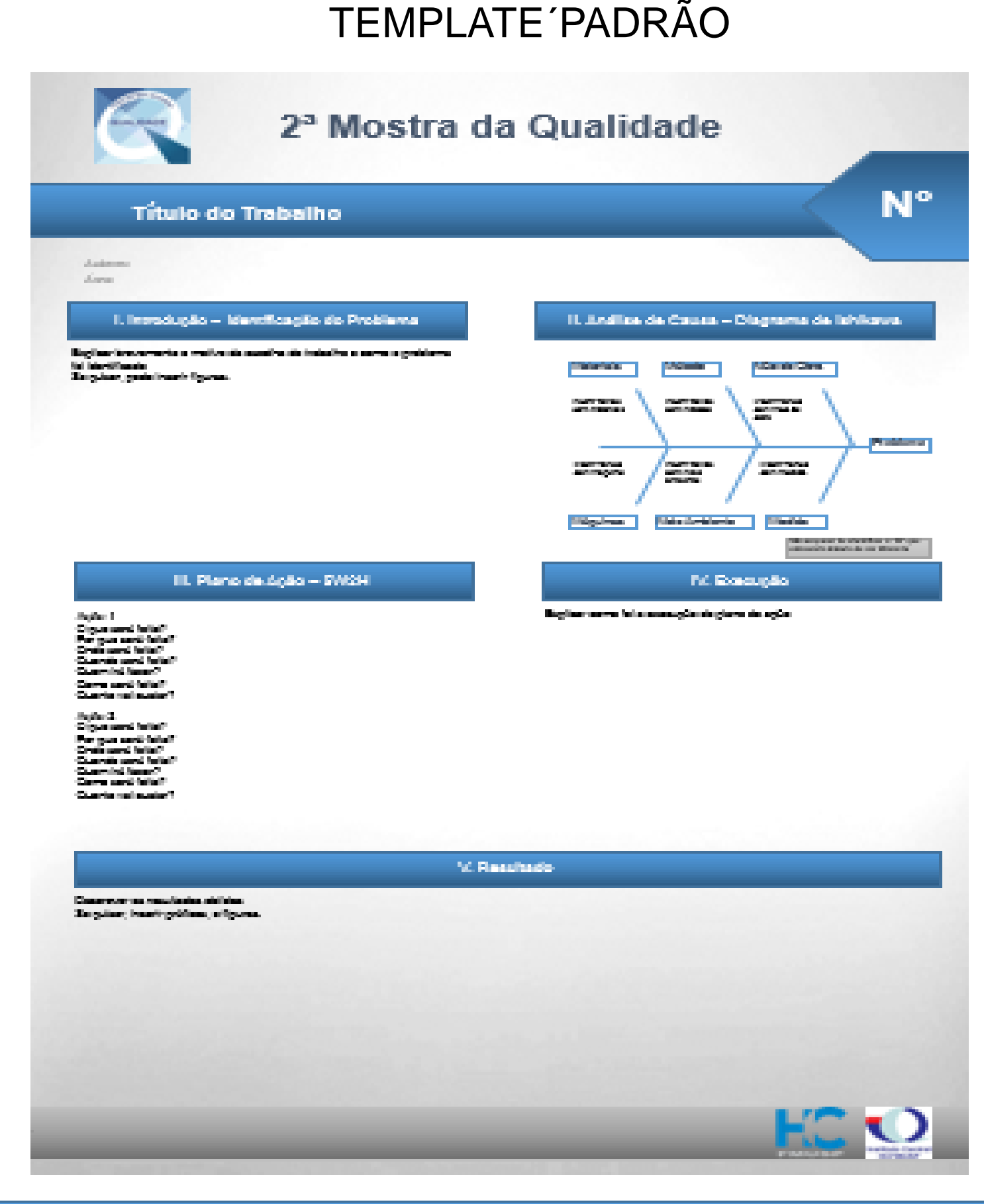

\section{Resultados}

Em 2017, foram inscritos 21 trabalhos e em 2018, 34. Em ambos os eventos houve forte engajamento das equipes na elaboração e visitação dos pôsteres. Os trabalhos apresentados no $2^{0}$ ano demonstram maior maturidade no uso das ferramentas da qualidade $e$ acompanhamento dos resultados. Como destaque, observamos que a maior parte se refere a trabalhos com interação entre áreas, traduzidos pelas primeiras premiações nos dois eventos: Enfermagem e Engenharia Clínica e Farmácia e Enfermagem.
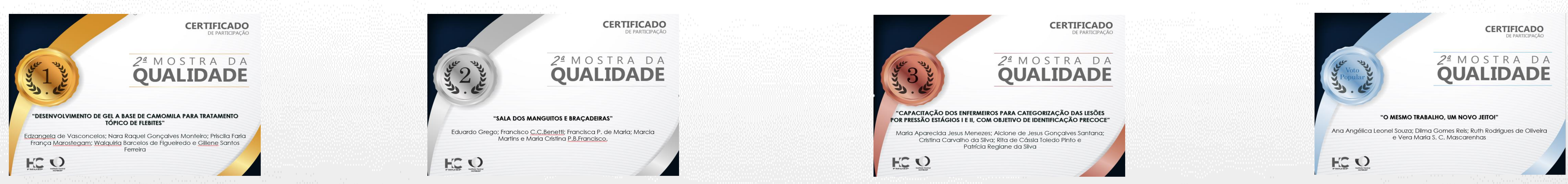

\section{Conclusão}

Observamos que o envolvimento das equipes de forma multiprofissional ao longo do tempo vem se fortalecendo. A utilização, entendimento e a aplicabilidade das ferramentas da Qualidade está se tornando um hábito para as equipes, fortalecendo a cultura da qualidade e segurança do paciente.
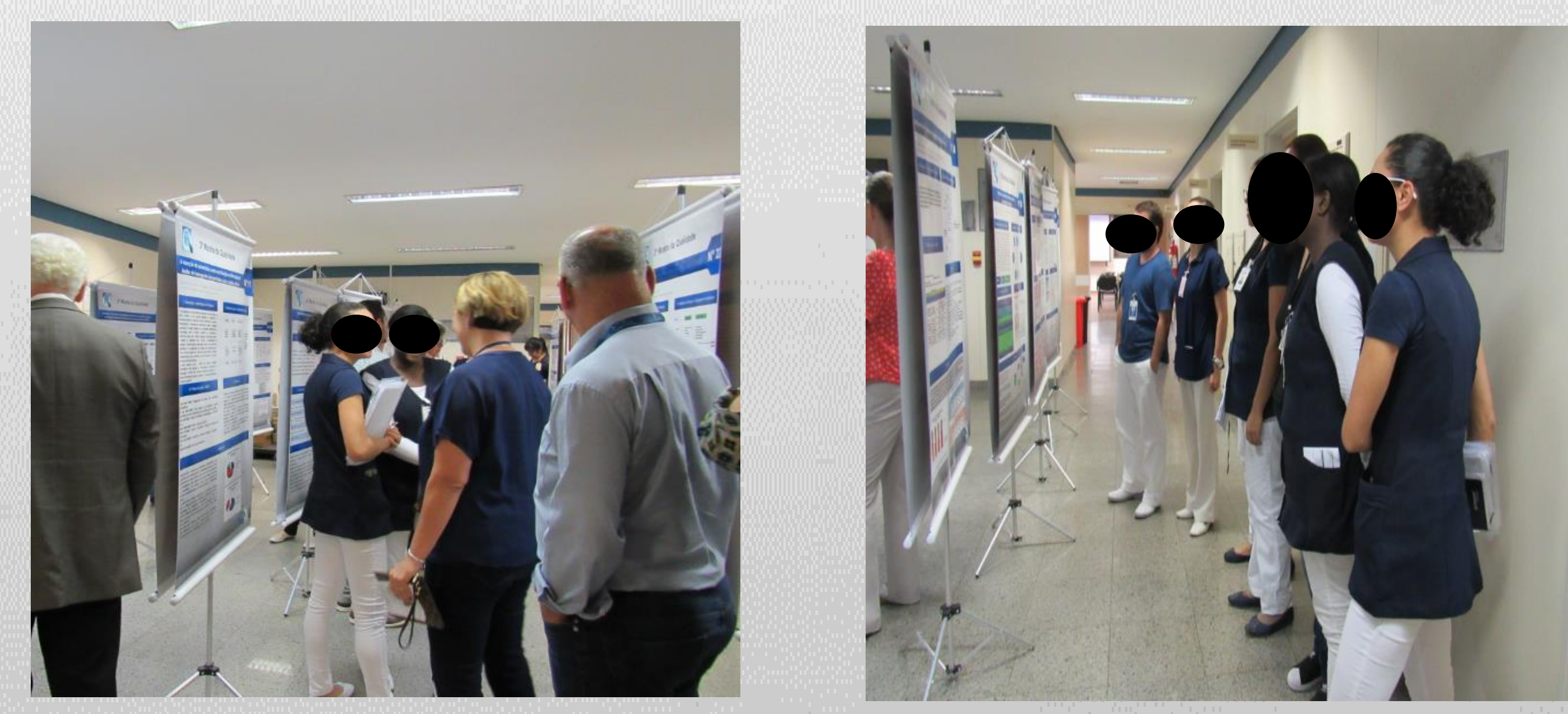

Bibliografia: DEMING, W. E. Qualidade: a revolução na administração. São Paulo: Marques-Saraiva, 1990.

MALIK, A. M., SCHIESARI, L. M. C. Qualidade na gestão local de serviços e ações de saúde. São Paulo: Peirópolis, 1998. 